\title{
The gps $X$ gene encoding a glycosyltransferase is important for polysaccharide production and required for full virulence in Xanthomonas citri subsp. citri
}

Jinyun $\mathrm{Li}^{1,2}$ and Nian Wang ${ }^{1 *}$

\begin{abstract}
Background: The Gram-negative bacterium Xanthomonas citri subsp. citri (Xac) causes citrus canker, one of the most destructive diseases of citrus worldwide. In our previous work, a transposon mutant of Xac strain 306 with an insertion in the XAC3110 locus was isolated in a screening that aimed at identifying genes related to biofilm formation. The XAC3110 locus was named as bdp24 for biofilm-defective phenotype and the mutant was observed to be affected in extracellular polysaccharide (EPS) and lipopolysaccharide (LPS) biosynthesis and cell motility. In this study, we further characterized the bdp24 (XAC3110) gene (designated as gpsX) using genetic

complementation assays and expanded the knowledge about the function of the gps $X$ gene in $X a c$ pathogenesis by investigating the roles of gpsX in EPS and LPS production, cell motility, biofilm formation on host leaves, stress tolerance, growth in planta, and host virulence of the citrus canker bacterium.

Results: The gps $X$ gene encodes a putative glycosyltransferase, which is highly conserved in the sequenced strains of Xanthomonas. Mutation of gps $X$ resulted in a significant reduction of the amount of EPS and loss of two LPS bands visualized on sodium dodecylsulphate- polyacrylamide gels. Biofilm assays revealed that the gps $X$ mutation affected biofilm formation by Xac on abiotic and biotic surfaces. The gps X mutant showed delayed bacterial growth and caused reduced development of disease symptoms in susceptible citrus leaves. The gps $X$ mutant was more sensitive than the wild-type strain to various stresses, including the $\mathrm{H}_{2} \mathrm{O}_{2}$ oxidative stress. The mutant also showed attenuated ability in cell motility but not in flagellar formation. Quantitative reverse transcription-PCR assays indicated that mutation of gpsX did not affect the expression of virulence genes such as pthA in Xac strain 306. The affected phenotypes of the gps $X$ mutant could be complemented to wild-type levels by the intact gps $X$ gene.

Conclusions: Taken together, our data confirm that the gps $X$ gene is involved in EPS and LPS synthesis and biofilm formation in Xac and suggest that the gpsX gene contributes to the adaptation of Xac to the host microenvironments at early stage of infection and thus is required for full virulence on host plants.
\end{abstract}

\section{Background}

Citrus canker, caused by the Gram-negative plant pathogenic bacterium Xanthomonas citri subsp. citri (Xac) (syn. Xanthomonas axonopodis pv. citri) [1,2], is one of the most important diseases of citrus crop worldwide [3]. Citrus canker is widely distributed in wet subtropical

\footnotetext{
* Correspondence: nianwang@ufl.edu

${ }^{1}$ Citrus Research and Education Center, Department of Microbiology and Cell Science, University of Florida, IFAS, 700 Experiment Station Road, Lake Alfred FL 33850, USA

Full list of author information is available at the end of the article
}

citrus growing areas and affects most commercial citrus varieties $[3,4]$. The canker symptom is characterized by raised necrotic lesions on leaves, stems and fruit of infected trees; and in severe cases, defoliation, twig dieback, general tree decline, blemished fruit and premature fruit drop can occur $[3,4]$. Wind-blown rain is the primary short- to medium-distance spread mechanism for citrus canker and long-distance dissemination is usually caused by transportation of infected citrus fruits and plant materials [5]. The decrease of yield and less value or entirely unmarketable of infected fruit are responsible
C Biomed Central

C 2012 Li and Wang; licensee BioMed Central Ltd. This is an Open Access article distributed under the terms of the Creative Commons Attribution License (http://creativecommons.org/licenses/by/2.0), which permits unrestricted use, distribution, and reproduction in any medium, provided the original work is properly cited. 
for serious economic losses [3]. Moreover, this disease has a significant impact on commerce due to restrictions to national and international fruit trade from cankeraffected areas [3]. Economic losses are also resulting from costly eradication programs and heave use of chemical treatments such as copper-based bactericides for prevention from and control of citrus canker disease [6].

Several members of the genus Xanthomonas, including $X a c$, have been extensively studied as model organisms to dissect the mechanisms of bacterium-plant interactions, including the molecular basis of pathogenesis and plant disease resistance [7-9]. Xac is considered to be a hemibiotrophic pathogen because it is able to obtain nutrients from living host cells, multiply in the apoplast (intercellular spaces) and then infect neighbouring tissues, after invading citrus host directly through natural openings, such as stomata, and through wounds [4]. The apoplast is a nutrient-limited environment that is guarded by plant defenses [10]. Xac, like many other plant pathogenic bacteria, has evolved several strategies to adapt to and successfully colonize this in planta niche by overcoming the plant defense and creating a favourable environment for bacterial growth, which include, among others, the type III secretion system (TTSS) and its effectors, cell wall degrading enzymes, and bacterial polysaccharides [8]. Bacterial polysaccharides of plant pathogenic bacteria, including extracellular polysaccharides (EPS), lipopolysaccharides (LPS) and capsular polysaccharides (CPS), have been shown to play a role in a number of different diseases. They collectively or individually contribute to the bacterial growth and survival in planta, and also are involved in the bacterium-plant interaction [8].

Progress has been made in elucidating the biosynthesis of bacterial polysaccharides over the decades [11]. The biosynthesis of bacterial polysaccharides occurs in successive steps. Firstly, nucleotide sugars are produced, which provide specifically activated monosaccharides as precursors for the subsequent synthesis steps. Secondly, monosaccharide moieties from the nucleotide sugar precursors are sequentially transferred by highly specific glycosyltransferases (GTs) to sugar or nonsugar acceptors, resulting in the formation of saccharide repeating units. Finally, the repeating units are polymerized and the polymer is exported from the cell. Bacterial GTs have been reported to be involved not only in the biosynthesis of EPS, LPS, CPS, peptidoglycans, and glycolipids, but also in protein and lipid glycosylation, showing enormous diversity of biological functions and substrates [12-14].

Much effort has been made to identify genes that encode GTs, their enzymatic functions, and the structures of these enzymes. Currently, there are more than 94 GT families in the Carbohydrate-Active EnZymes (CAZy) database (http://www.cazy.org) based on amino acid sequence similarities $[15,16]$. Two main three-dimensional folds, named
GT-A and GT-B, have been observed for structures of nucleotide sugar-dependent GTs $[12,13]$. There is high sequence variability, although the relatively low structural variety and it is not yet possible to reliably predict the precise function of a given GT.

Mutations in GTs encoding genes have profound biological effects in a variety of bacteria. For example, mutation in spsA of Bacillus subtilis resulted in an altered spore coat [17]. In Escherichia coli strain 2787 (O126: $\mathrm{H} 27)$, an aah-deletion mutant was attenuated in adherence to host cells [18], and the pgaC mutant of E. coli $\mathrm{K}-12$ was impaired in surface binding, intercellular adhesion, and biofilm formation [19]. Mutation of orf $N$ in Pseudomonas aeruginosa PAK affected the flagellin glycosylation [20]. In X. campestris pv. campestris strain 8004, mutation of $x a g B$ (XC_3555) led to decreased EPS production, abolished biofilm formation and attenuated bacterial resistance to oxidative stress [21], and the $X C \_3814$ mutant was significantly reduced both in EPS production and virulence on host plants [22]; while the $r f b C$ mutation in Xac strain 306 resulted in altered $\mathrm{O}$-antigen of LPS, reduced biofilm formation and attenuated bacterial resistance to environmental stresses [23].

In our previous work, an EZ-Tn5 transposon mutant of $X a c$ strain 306 with an insertion in the XAC3110 locus was isolated in a screening that aimed at identifying genes involved in biofilm formation. The XAC3110 locus was named as $b d p 24$ for biofilm-defective phenotype and the mutant was observed to be affected in EPS and LPS biosynthesis, cell motility and biofilm formation on abiotic surfaces [24]. Due to the nature of our previous study in genome-wide identification of biofilm related genes, we focused on big picture rather than individual genes. It is necessary to further characterize the novel genes identified in our previous study and provide conclusive genetic evidence in complementation. In this study, we further characterized the $b d p 24$ (XAC3110) gene (renamed as gpsX) that encodes a putative glycosyltransferase using genetic complementation assays. The data obtained confirmed that the novel gene gps $X$ plays a role in EPS and LPS biosynthesis, cell motility, biofilm formation on abiotic surfaces and host leaves, stress tolerance, growth in planta, and host virulence of the citrus canker bacterium. These findings suggest that the gpsX gene contributes to the adaptation of Xac to the host microenvironments at early stage of infection and thus is required for full virulence on host plants.

\section{Results}

The gps $X$ gene encodes a glycosyltransferase involved in polysaccharide biosynthesis in $X$. citri subsp. citri

The XAC3110 locus was identified as a biofilm formation-related gene of $b d p 24$ that may be involved in EPS and LPS biosynthesis, following screening a transposon 
insertion mutant library of Xac strain 306 in our earlier work [24]. The XAC3110 open reading frame (ORF) is $2028 \mathrm{bp}$ in length and located in the genome sequence at position 3655217-3657244 (Figure 1). XAC3110 consists of a single transcriptional unit, whereas the adjacent upstream and downstream genes were transcribed separately from this ORF in reverse orientation [25]. XAC3110 was annotated as a 675 aa glycosyltransferase [7]. The predicted pI and molecular weight (MW) of the putative enzyme are 6.67 and $73.9 \mathrm{kD}$ (http://web.expasy. org/compute_pi/), respectively. The predicted protein contained a glycosyltransferase family 2 domain (PF00535, 2.00e-28) (residues 50-216) at the N-terminal and a UDP-Glycosyltransferase/glycogen phosphorylase superfamily domain (SCOP:d1f6da_, 2.00e-12) (residues 340-660) at the C-terminal (Figure 1). In addition, PSIBLAST analysis revealed that the XAC3110 belongs to glycosyltransferase family II (GT-2) in the Pfam Protein Family Database [26]. The predicted XAC3110 protein processes several conserved catalytic residues of glycosyltransferases including the DXD motif $\left(\mathrm{D}^{234} \mathrm{TD}^{236}\right)$ for the divalent metal ion binding in glycosyltransferases with a common GT-A structural fold [27,28] (Figure 2). Database search revealed that XAC3110 are highly conserved in other sequenced Xanthomonas species, including $X$. oryzae, $X$. campestris, $X$. fuscans, $X$. perforans, $X$. vesicatoria, X. gardneri, and X. albilineans, with over $70 \%$ amino acid identity (Table 1). All these homologues are putative glycosyltransferases with unknown functions. Their homologues with about $35-70 \%$ identity are also present in Acetobacter aceti, Clostridium spp., Xylella fastidiosa, Chlorobium phaeobacteroides, Saccharopolyspora erythraea, Thiorhodococcus drewsii, Rhodospirillum centenum, Stenotrophomonas spp., and Burkholderia spp.; among which, several are putative GT-2 proteins (data not shown). These findings strongly suggested that XAC3110 may be a member of GT-2. Collectively, given the role in polysaccharide production (see below), the $b d p 24$ (XAC3110) gene was renamed as gpsX (glycosyltransferase for polysaccharide synthesis in $X$. citri subsp. citri).

To exclude the possibility of multiple EZ-Tn 5 insertions in the genome of the gpsX mutant 223 G4 (gpsX-) (Table 2), complementation assays were performed for this mutant. The complementary plasmid pJU3110 with intact gps $X$ (Table 2) was transformed into the mutant 223 G4 (gpsX-), and the complemented strain C223G4 (gps $X+)$ was assayed for EPS and LPS production. The results showed that the total EPS production of the gps $X$ mutant in NB containing $2 \%$ glucose at 24 hours post inoculation could be restored to the wild-type level by the plasmid pJU3110, but not by the empty vector pUFR053 (Figure 3A). Both the mutant strains 223 G4 (gps $X_{-}$) and $223 \mathrm{G} 4 \mathrm{~V}$ (gps $\mathrm{X}_{-}$) produced significantly less

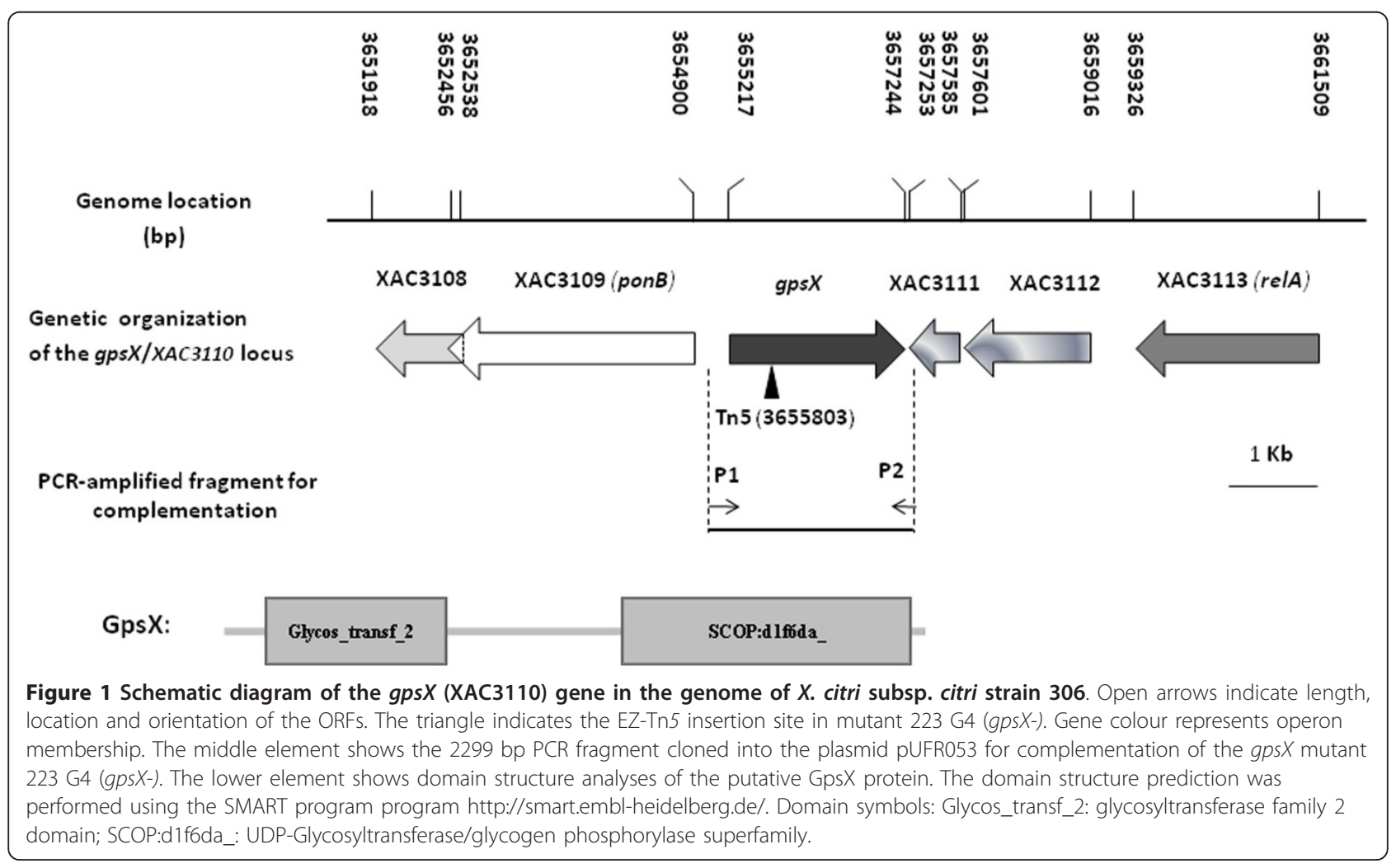


EPS than the wild-type strain 306. The complemented strain C223G4 ( $g p s X+$ ) had a similar level of EPS production to the wild-type strain. Sodium dodecylsulphatepolyacrylamide gel electrophoresis (SDS-PAGE) analysis showed that LPS of the gpsX mutant was different from that of the wild-type strain 306 (Figure 3B). Two bands corresponding to the $\mathrm{O}$-antigen containing LPS were completely lost in the gps $X$ mutant, compared to wild type strain 306. The LPS pattern of the complemented gps $X$ mutant was similar with that of the wild-type strain 306. The empty vector pUFR053 did not complement LPS biosynthesis in the gps $X$ mutant (Figure 3B). These findings indicated that the transposon insertion mutation in gps $X$ could be complemented by the wild type ORF in trans and, the gps $X$ locus is involved in polysaccharides biosynthesis in $X$. citri subsp. citri.

To further confirm the role of gps $X$ in polysaccharides biosynthesis, the EPS production of the mutants grown in XVM2 liquid medium supplemented with $2 \%$ of various carbohydrates was quantitatively estimated. As summarized in Table 3, the gps $X$ mutant produced about $30-50 \%$ less EPS than the wild-type strain 306 when cultured in fructose-, galactose-, glucose-, maltose-, mannose-, or sucrose-containing medium; while the EPS yield of the complemented mutant strains showed no significant difference from that of the wildtype. In contrast, no significant difference in capsule staining was observed between the gps $X$ mutant strain 
Table 1 GpsX/XAC3110 homologues in Xanthomonas spp

\begin{tabular}{|c|c|c|c|c|c|}
\hline \multirow[t]{2}{*}{ Strains $^{a}$} & \multicolumn{4}{|c|}{ Homologue } & \multirow[b]{2}{*}{ Identity (\%) $^{c}$} \\
\hline & Gene/locus_tag & Putative product & Size (aa) & Domain structure $^{b}$ & \\
\hline Xac 306 & gpsX/XAC3110 & glycosyltransferase & 675 & Glycos_transf_2 (1); SCOP:d1f6da_(1) & \\
\hline Xpe 91-118 & XPE_2818 & glycosyltransferase & 700 & Glycos_transf_2 (1); SCOP:d1f6da_(1) & 97 \\
\hline XoO KACC10331 & X001738 & glycosyltransferase & 675 & Glycos_transf_2 (1); Glycos_transf_1(1); & 94 \\
\hline XOO MAFF311018 & X0O_1639 & glycosyltransferase & 700 & Glycos_transf_2 (1); & 94 \\
\hline Xoo PXO99A & PXO_01594 & glycosyltransferase & 700 & Glycos_transf_2 (1) & 94 \\
\hline Xoc BLS256 & Xoryp_010100016275 & glycosyltransferase & 700 & Glycos_transf_2 (1); Glycos_transf_1(1); & 94 \\
\hline XCV NCPPB702 & XcampvN_010100002613 & glycosyltransferase & 698 & Glycos_transf_2 (1); Glycos_transf_1(1); & 94 \\
\hline Xau ICPB10535 & XAUC_30140 & glycosyltransferase & 694 & Glycos_transf_2 (1); Glycos_transf_1(1); & 93 \\
\hline Xau ICPB11122 & XAUB_29140 & glycosyltransferase & 694 & Glycos_transf_2 (1); SCOP:d1f6da_(1) & 93 \\
\hline Xve ATCC35937 & XVE_0383 & glycosyltransferase & 701 & Glycos_transf_2 (1); SCOP:d1f6da_(1) & 93 \\
\hline XCV 85-10 & XCV3242 & glycosyltransferase & 694 & Glycos_transf_2 (1); SCOP:d1f6da_(1) & 92 \\
\hline Xga ATCC19865 & XGA_4540 & glycosyltransferase & 700 & Glycos_transf_2 (1); SCOP:d1f6da_(1) & 92 \\
\hline Xcc 8004 & $X C_{-} 1175$ & glycosyltransferase & 675 & Glycos_transf_2 (1); Glycos_transf_1(1); & 90 \\
\hline XсC ATCC33913 & XCC2933 & glycosyltransferase & 700 & Glycos_transf_2 (1); Glycos_transf_1(1); & 89 \\
\hline Xсc B100 & xccb100_1219 & hypothetical protein & 700 & Glycos_transf_2 (1); SCOP:d1f6da_(1) & 89 \\
\hline Xer $756 C$ & XCR_3304 & glycosyltransferase & 700 & Glycos_transf_2 (1); SCOP:d1f6da_(1) & 89 \\
\hline Xan GPE PC73 & XALC_2250 & glycosyltransferase & 698 & Glycos_transf_2 (1); Glycos_transf_1(1); & 70 \\
\hline
\end{tabular}

${ }^{a}$ Xac 306: X. axonopodis pv. citri strain 306 (GenBank accession number: AE008923); Xpe 91-118: X. perforans 91-118 (AEQW00000000); Xoo KACC10331: X. oryzae pv. oryzae KACC10331 (AE0135983); Xoo MAFF311018: X. oryzae pv. oryzae MAFF311018 (AP008229); Xoo PXO99A: X. oryzae pv. oryzae PXO99A (CP000967); Xoc BLS256: X. oryzae pv. oryzicola BLS256 (AAQN00000000); XCV NCPPB702: X. campestris pv. vasculorum NCPPB702 (ACHS00000000); Xau ICPB10535: X. fuscans subsp. aurantifolii ICPB10535 (ACPY00000000); Xau ICPB11122: X. fuscans subsp. aurantifolii ICPB11122 (ACPX00000000); Xve ATCC35937: X. vesicatoria ATCC35937 (AEQV00000000); Xcv 85-10: X. campestris pv. vesicatoria 85-10 (AM039952); Xga ATCC19865: X. gardneri ATCC19865 (AEQX00000000); Xcc 8004: X. campestris pv. campestris 8004 (CP0000509); Xcc ATCC33913: X. campestris pv. campestris ATCC 33913 (AE008922); Xcc B100: X. campestris pv. campestris B100 (AM920689); Xcr 756 C: $X$. campestris pv. raphani 756 C (CP002789); Xan GPE PC73: X. albilineans GPE PC73(FP565176). ${ }^{b}$ Domains were predicted by the SMART program http:// smart.embl-heidelberg.de/. Domain symbol: Glycos_transf_2, glycosyltransferase family 2 domain; SCOP:d1f6da_: UDP-Glycosyltransferase/glycogen phosphorylase superfamily; Glycos_transf_1, glycosyltransferase family 1 domain. The total number of the domains was indicated in the bracket. 'According to a BLASTP search.

and the wild-type strain 306 in capsule assays (data not shown).

GpsX was required for full virulence and growth of $X$. citri subsp. citri in host plants

Since both EPS and LPS have been demonstrated to contribute to host virulence of $X$. citri subsp. citri $[23,34,35]$, we were interested in determining whether the gps $X$ gene is associated with pathogenicity of the canker bacterium.
The virulence of the gps $X$ mutant was assessed on the host plant grapefruit using two inoculation methods: pressure infiltration and spray. Upon infiltration at a concentration $10^{5}$ colony-forming units $(\mathrm{cfu}) / \mathrm{ml}$, no disease symptom was observed on the gps $X$ mutant or wild type strain inoculated leaves at 7 days post inoculation (dpi); however, the gps $X$ mutant induced less canker lesions than the wild-type strain 306 at 14 dpi (Figure 4A). When infiltrated at a higher concentration $\left(10^{8} \mathrm{cfu} / \mathrm{ml}\right)$,

Table 2 Bacterial strains and plasmidsa

\begin{tabular}{|c|c|c|}
\hline Strains and plasmids & Characteristics & Reference or source \\
\hline \multicolumn{3}{|l|}{ Strains } \\
\hline E. coliDH5 $\alpha$ & $\mathrm{F}^{-}$recA1 endA1 hsdR17 supE44 thi-1 gyrA96 relA1 $\triangle$ (argE-lacZYA)169 ф80 lazA $\triangle$ M15 & [29] \\
\hline HB101 & $\mathrm{F}^{-}$supE44, hsdS20(rB- $\left.m B^{-}\right)$, recA13, ara-14, proA2, lacY1, galK2, rpsL20, xyl-5, mtl-1, leuB6, thi & [30] \\
\hline \multicolumn{3}{|l|}{$X$. citri subsp. citri } \\
\hline 306 & Syn. X. axonopodis pv. citri strain 306; wild type, $\mathrm{Rf}^{r}$ & [31] \\
\hline $223 \mathrm{G} 4$ (gps $X-)$ & gpsX (XAC3110):: EZ-Tn5 derivative of strain $306, \mathrm{Km}^{r}$, Rfr & [24] \\
\hline 223G4V (gpsX-) & 223G4 (gpsX-) containing pUFR053, $\mathrm{Cm}^{r}, \mathrm{Gm}^{r}, \mathrm{Km}^{r}, \mathrm{Rf}^{r}$ & This study \\
\hline C223G4 (gpsX+) & 223G4 (gpsX-) containing pJU3110, $\mathrm{Cm}^{r}, \mathrm{Gm}^{r}, \mathrm{Km}^{r}, \mathrm{Rf}^{r}$ & This study \\
\hline \multicolumn{3}{|l|}{ Plasmids } \\
\hline pRK2013 & ColE1 $\mathrm{Km}^{\mathrm{r}} \mathrm{Tra}^{+}$, conjugation helper plasmid & [32] \\
\hline pUFR053 & IncW Mob mob(P) lacZ+ $\mathrm{Par}^{+}, \mathrm{Cm}^{r}, \mathrm{Gm}^{r}$, shuttle vector & [33] \\
\hline pJU3110 & 2,299-bp Kpnl- HindIII fragment containing wild-type gpsX cloned in pUFR053; $\mathrm{Cm}^{r}, \mathrm{Gm}^{\mathrm{r}}$ & This study \\
\hline
\end{tabular}

${ }^{a} \mathrm{Ap}^{r}, \mathrm{Cm}^{r}, \mathrm{Gm}^{r}, \mathrm{Km}^{r}$, and $\mathrm{Rf}^{\mathrm{r}}$ indicate resistance to ampicillin, chloromycetin, gentamicin, kanamycin and rifamycin, respectively. 


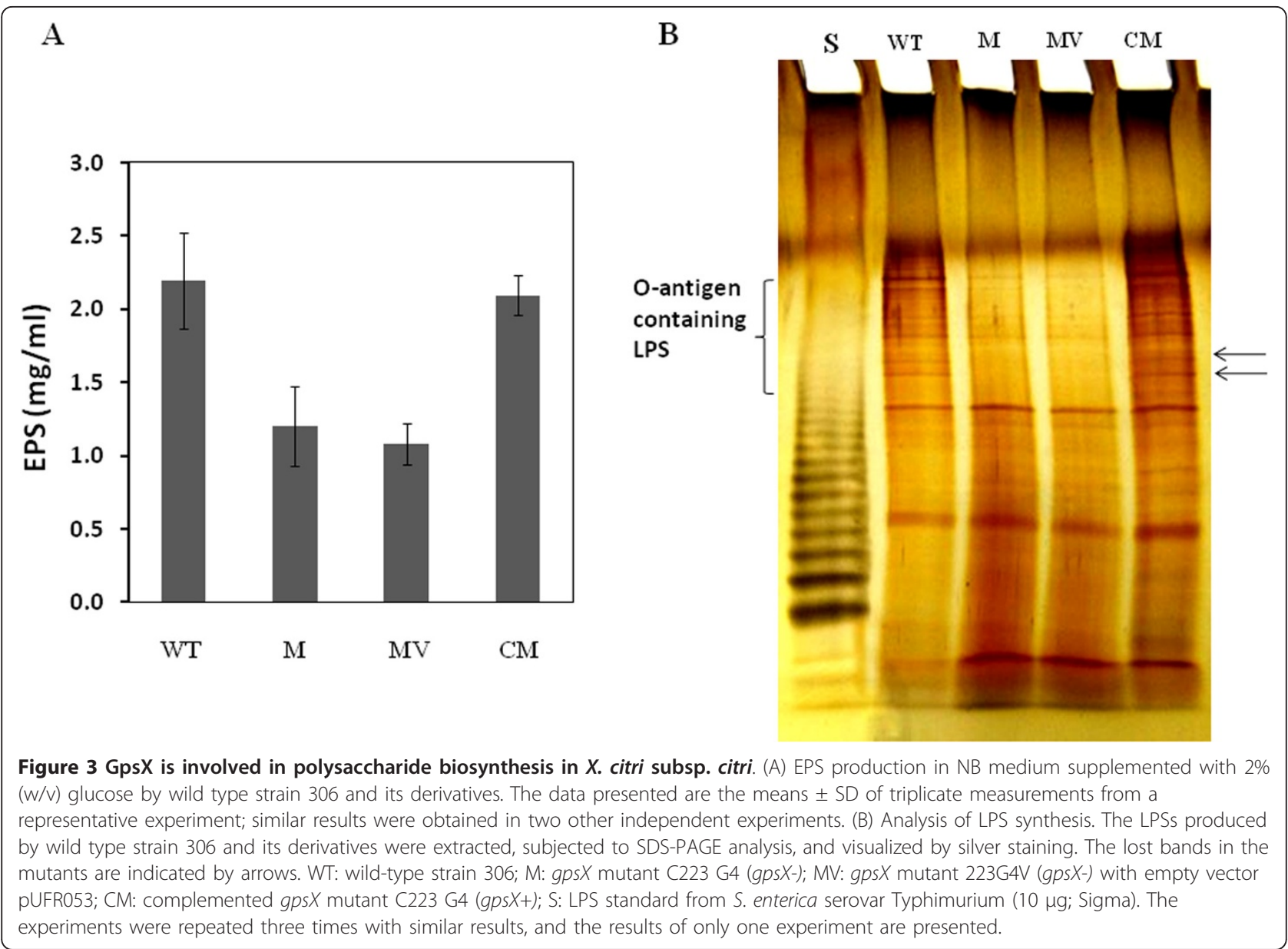

the gps $X$ mutant induced significantly less lesions than wild type at $7 \mathrm{dpi}$, but caused similar disease symptoms as wild type at $14 \mathrm{dpi}$. In both cases, the complemented mutant strain with the intact gps $X$ cloned in pUFR053 showed no difference from the wild type strain (Figure $4 \mathrm{~A})$. Plant inoculation by spray, a method that mimics the natural infection, showed that the gps $X$ mutant was reduced in virulence on grapefruit compared with the wild-type strain 306. After 21 days post inoculation the number of canker lesions on leaves infected with the gps $X$ mutant was significantly less than that inoculated with wild type strain. Symptom induction by the gps $X$ mutant could be restored to the wild-type level by complementary plasmid pJU3110, but not by the empty vector (Figure 4B).

Although there were no differences between the wild type and the gps $X$ mutant strains in the ability to grow in XVM2 medium (data not shown), the growth of gps $X$ mutant 223 G4 (gpsX-) was significantly reduced in planta compared to the growth of the wild-type strain. After inoculation by infiltration at $10^{5} \mathrm{cfu} / \mathrm{ml}$, the bacterial population of the gps $X$ mutant moderately reduced in planta, and between 24 and $48 \mathrm{~h}$, the bacterial population began to increase; whereas the bacterial population of the wild type strain 306 continued to increase after inoculation (Figure 5A). The bacterial population

Table 3 EPS production in X.citri subsp. citri strainsa

\begin{tabular}{|c|c|c|c|c|c|c|c|}
\hline \multirow[t]{2}{*}{ Strain } & \multicolumn{6}{|c|}{ EPS yield ( $g / L)$} & \multirow[b]{2}{*}{ Xylose } \\
\hline & Fructose & Galactose & Glucose & Maltose & Mannose & Sucrose & \\
\hline 306 & $1.73 \pm 0.23 a$ & $1.08 \pm 0.24 \mathrm{a}$ & $1.83 \pm 0.17 \mathrm{a}$ & $1.22 \pm 0.11 \mathrm{a}$ & $1.54 \pm 0.27 \mathrm{a}$ & $1.62 \pm 0.18 a$ & $1.38 \pm 0.21 \mathrm{a}$ \\
\hline $223 G 4$ (gpsX-) & $0.83 \pm 0.14 b$ & $0.64 \pm 0.11 b$ & $1.22 \pm 0.25 b$ & $0.75 \pm 0.19 b$ & $0.94 \pm 0.12 b$ & $0.68 \pm 0.11 b$ & $1.15 \pm 0.17 \mathrm{a}$ \\
\hline C223G4 (gpsX+) & $1.91 \pm 0.36 a$ & $1.22 \pm 0.25 \mathrm{a}$ & $1.96 \pm 0.34 \mathrm{a}$ & $1.14 \pm 0.16 \mathrm{a}$ & $1.45 \pm 0.19 a$ & $1.76 \pm 0.31 \mathrm{a}$ & $1.53 \pm 0.25 a$ \\
\hline
\end{tabular}

${ }^{a}$ Strains were cultured in XVM2 liquid medium supplemented with various carbon sources. Data presented are means and standard errors of three replicates from one representative experiment and similar results were obtained in two other independent experiments. Different letters in each data column indicate significant differences at $P<0.05$ (Student's t-test). 


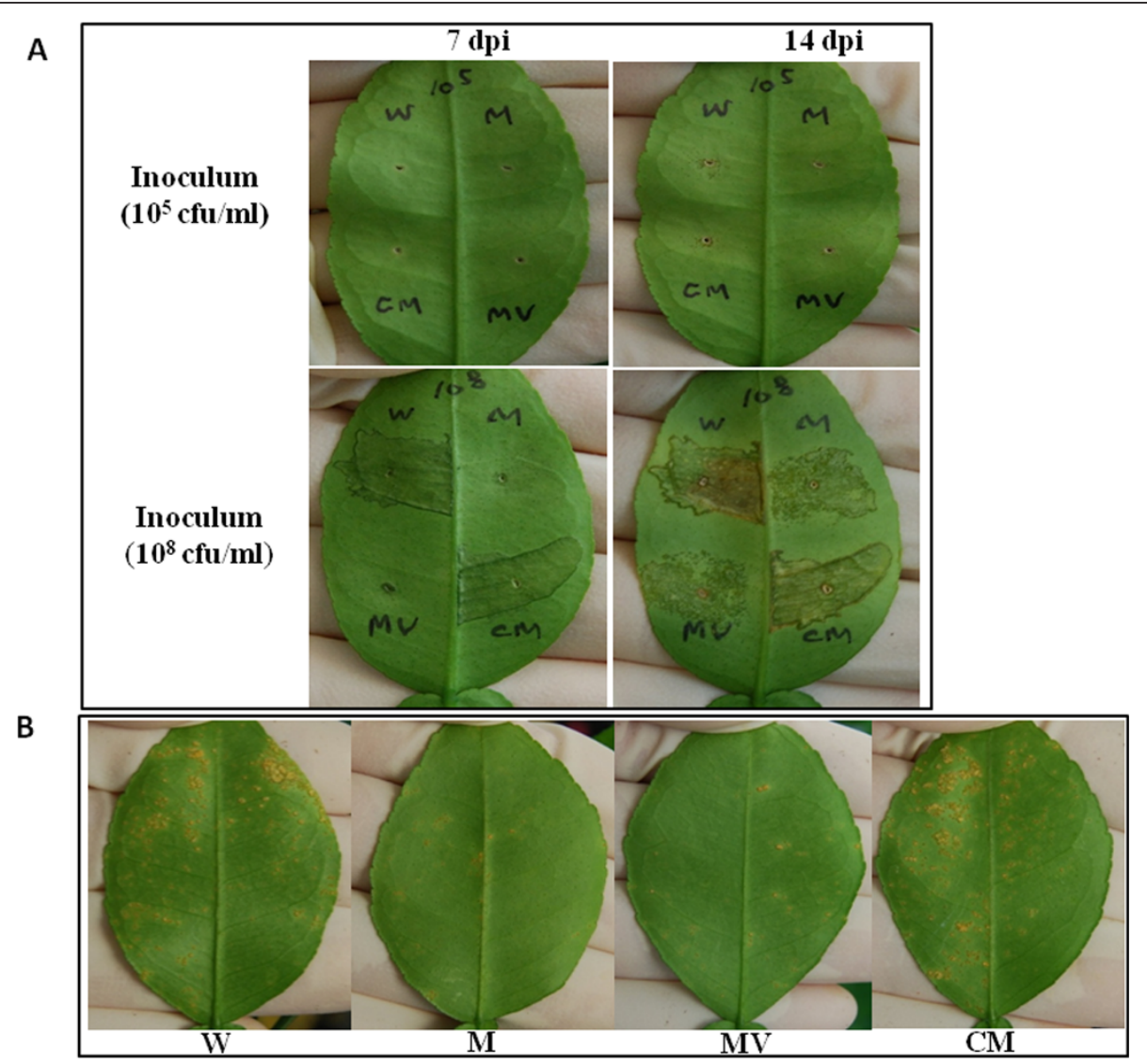

Figure $4 \mathrm{GpsX}$ is important for host virulence of $\boldsymbol{X}$. citri subsp. citri. (A) Suspensions of each strain [approximately $10^{5}$ and $10^{8} \mathrm{cfu} / \mathrm{ml}$, respectively] were inoculated into the intercellular spaces of fully expanded, immature grapefruit (C. paradise cv. Duncan) leaves by pressure infiltration with a needleless syringe. A representative leaf from four replicates was photographed at 7 and $14 \mathrm{dpi}$, respectively. W: wild-type strain 306; M: gpsX mutant 223 G4 (gpsX); MV: gpsX mutant 223G4V (gpsX-) with empty vector pUFR053; CM: complemented gpsX mutant C223G4 (gps $X+$ ). (B) Bacterial cell suspensions (approximately $10^{8} \mathrm{cfu} / \mathrm{ml}$ ) of wild-type strain 306 and its derivatives were inoculated onto fully expanded, immature grapefruit by spray. Images are representative of five independent replicates at $21 \mathrm{dpi}$.

of the gps $X$ mutant recovered from the infected leaves was approximately 10 to 100 -fold lower than that of the wild-type strain at each of the test points (Figure 5A). Similar differences in growth of the wild type and mutant strains were observed following infiltration at $10^{8} \mathrm{cfu} / \mathrm{ml}$ (Figure $\left.5 \mathrm{~B}\right)$. The bacterial population of the complemented strain was similar to that of the wildtype at each test point (Figure 5A and 5B). The populations of the gps $X$ mutant compared to wild type strain were also analyzed after inoculation via spraying and significant differences were observed. As shown in Figure 5C, after inoculation, the population of the wild type strain remained approximately constant until $4 \mathrm{dpi}$, whereas the population of the gps $X$ mutant declined significantly. At $4 \mathrm{dpi}$, the population size of the gps $X$ mutant was nearly 100 times lower than for the wild type strain. From that point forward, the population sizes of the gpsX mutant began to increase slowly, whereas growth of the wild type strain continued after inoculation, so that, at $14 \mathrm{dpi}$, the difference in population size was one to two orders of magnitude. The affected growth of the gps $X$ mutant was restored to wild type levels by complementation with the cloned gps $X$ gene (Figure 5C). Overall, these findings suggest that gps $X$ is required for $X$. citri subsp. citri to proliferate well and to achieve full virulence in host plants.

\section{Mutation in gps $X$ affected biofilm formation of $X$. citri subsp. citri on abiotic surfaces and host leaves}

Biofilm has been well characterized as a virulence trait in many plant pathogenic bacteria [36]. Our earlier study indicated that $g p s X$ is related to biofilm formation [24]. In order to confirm the role of gps $X$ in biofilm formation in $X$. citri subsp. citri, biofilm formation of the gps $X$ mutant was examined on three different kinds of surfaces: polystyrene, glass and host leaves. The gpsX mutant 223 G4 (gps $X$-) exhibited a significant reduction in biofilm formation both on polystyrene surface and in glass tubes compared to that of the wild-type, where the level of biofilm 
A

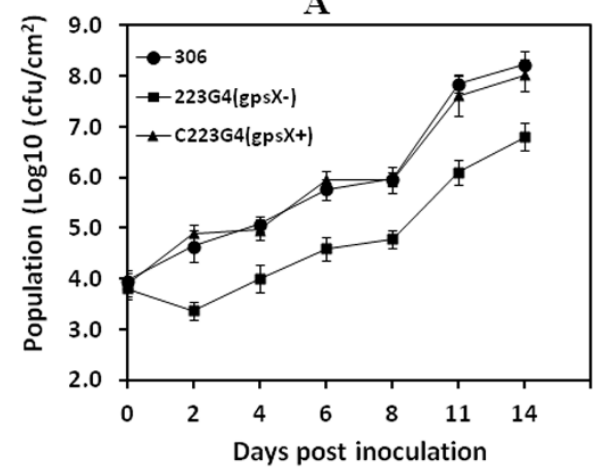

C

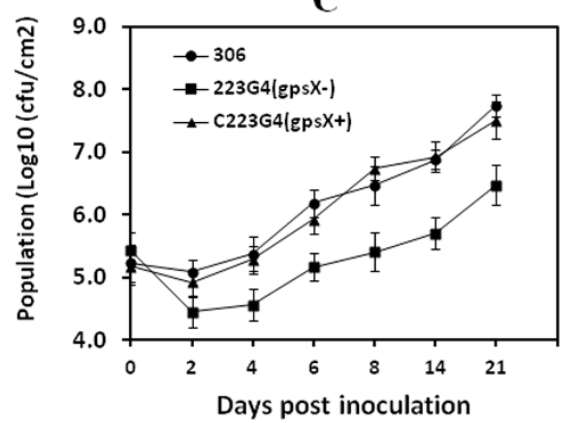

B

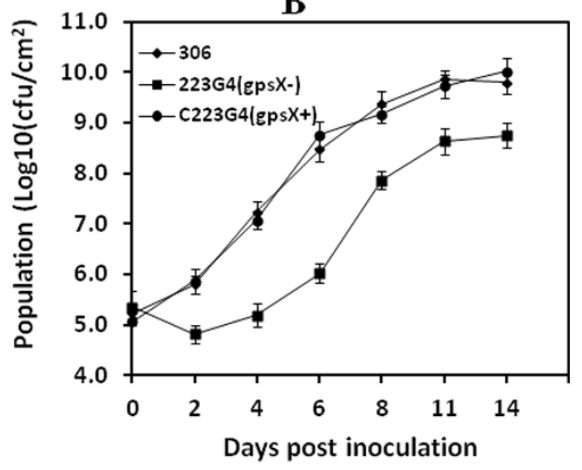

Figure $5 \mathrm{GpsX}$ is important for growth in planta of $X$. citri subsp. citri. (A) Growth of wild-type strain 306 and its derivatives in inoculated grapefruit leaves by pressure infiltration with a concentration at $10^{5} \mathrm{cfu} / \mathrm{ml}$. 306: wild-type strain 306; 223 G4(gpsX-): gpsX mutant; C223G4 (gpsX + ): complemented gpsX mutant. (B) Growth of wild-type strain 306 and its derivatives in inoculated grapefruit leaves by pressure infiltration with a concentration at $10^{8} \mathrm{cfu} / \mathrm{ml}$. (C) Growth of wild-type strain 306 and its derivatives in inoculated grapefruit leaves by spray with a concentration at $10^{8} \mathrm{cfu} / \mathrm{ml}$. Bacterial cells were extracted from the leaves at different time points after inoculation, plated on appropriate media after serial dilution, and colonies counted after a 2-day incubation at $28^{\circ} \mathrm{C}$. The values shown are means of three repeats and standard deviations. All the assays were repeated three times with similar results.

formation were approximately $30 \%$ and $40 \%$ of the wildtype level, respectively; and the complemented C223G4 $(g p s X+)$ strains were restored to levels similar to that of the wild-type strain (Figure 6A and 6B). Similar to the observations on polystyrene surface and in glass tubes, the gps $X$ mutant showed declined biofilm formation on citrus leaf surfaces and, the complemented C223G4 (gpsX+) strains were restored the wild-type levels (Figure 6C), suggesting that the gps $X$ gene is involved in biofilm formation of $X$. citri subsp. citri cells on citrus leaves. These findings confirmed that the gps $X$ gene is involved in biofilm formation in X. citri subsp. citri.

\section{Mutation of gpsX caused impairment in cell motility but no impact on flagellar formation}

Several studies have indicated that both EPS and LPS are associated with the flagella-independent motility in a couple of bacteria including $X$. citri subsp. citri $[21,24,37]$. To verify whether a mutation in $g p s X$ has any effect on the cell motility of $X$. citri subsp. citri, the gps $X$ mutant was evaluated for the mobile ability on swimming and swarming plates, respectively. The results showed that a significant reduction $(P<0.05$, student's t-test $)$ both in swimming and swarming motility was observed in the gps $X$ mutant $223 \mathrm{G} 4$ (gpsX-), compared with the wild-type strain (Figure 7 ). On the tested plates, the diameter of the growth zones resulting from migration away from the inoculation points on the agar surface were about $2.5 \mathrm{~cm}$ (swimming plates) and $2.0 \mathrm{~cm}$ (swarming plates) for the gps $X$ mutant, and $4.2 \mathrm{~cm}$ (swimming plates) and $3.0 \mathrm{~cm}$ (swarming plates) for the wild type. The diameter of the complemented strain and the wildtype strain were not significantly different, indicating that the mobility of the mutant could be restored to wild-type levels by gps $X$ in trans. Flagellum visualization assays using transmission electron microscope (TEM) showed that both the wild-type and the gps $X$ mutant strains formed a polar flagellum at the cell surface (data not shown), suggesting that mutation of gps $X$ has no impact on flagellar formation in Xac. These results indicated that the gps $X$ is implicated in bacterial motility in $X$. citri subsp. citri.

GpsX contributed to stress tolerance of $X$. citri subsp. citri The decrease in bacterial population in planta of the gps $X$ mutant immediately after inoculation (Figure 5A, B 


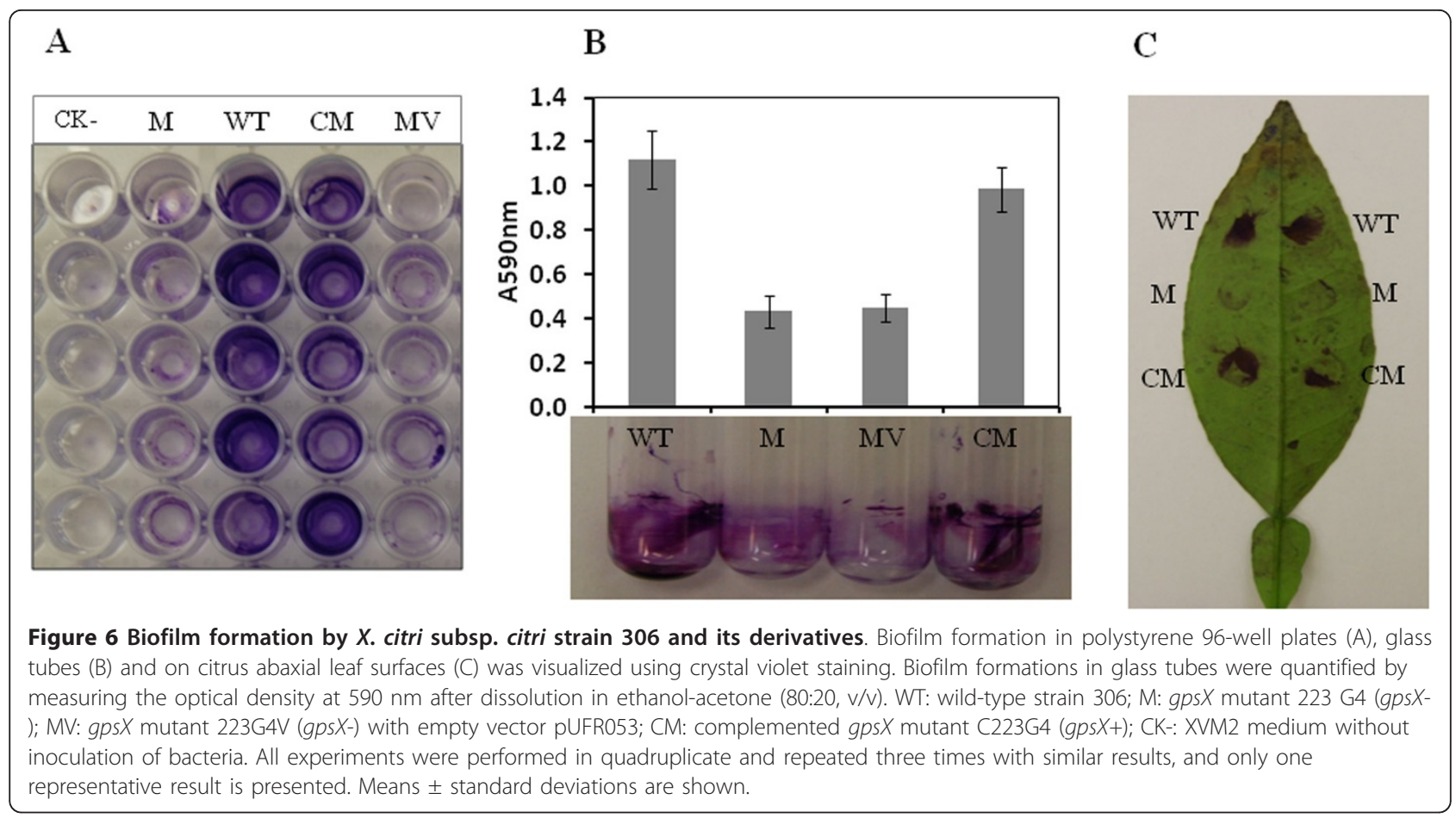

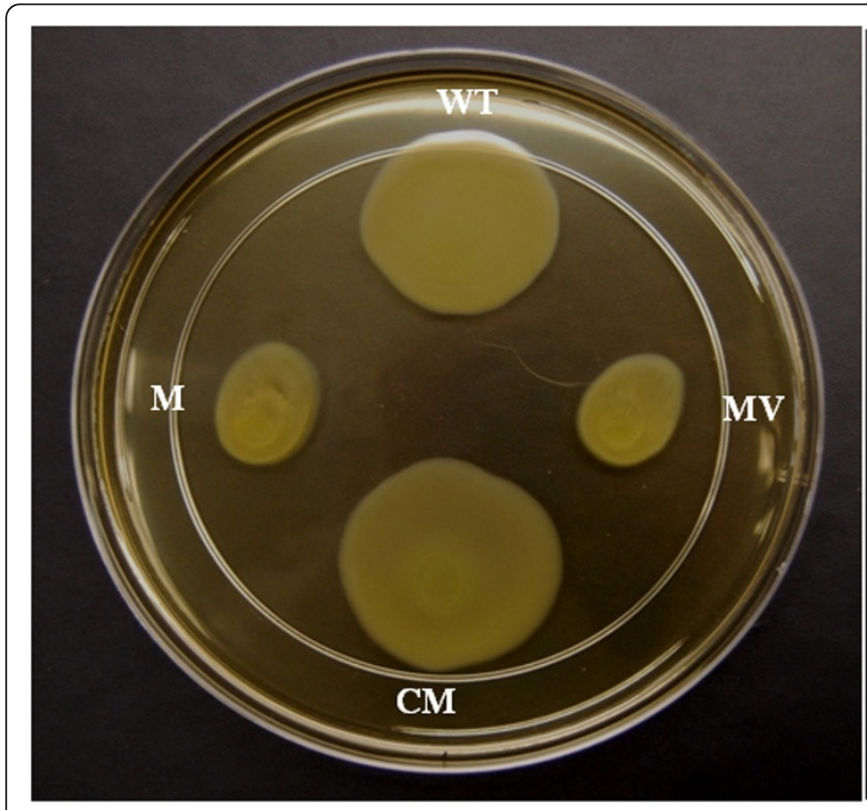

$0.25 \%$ agar plate

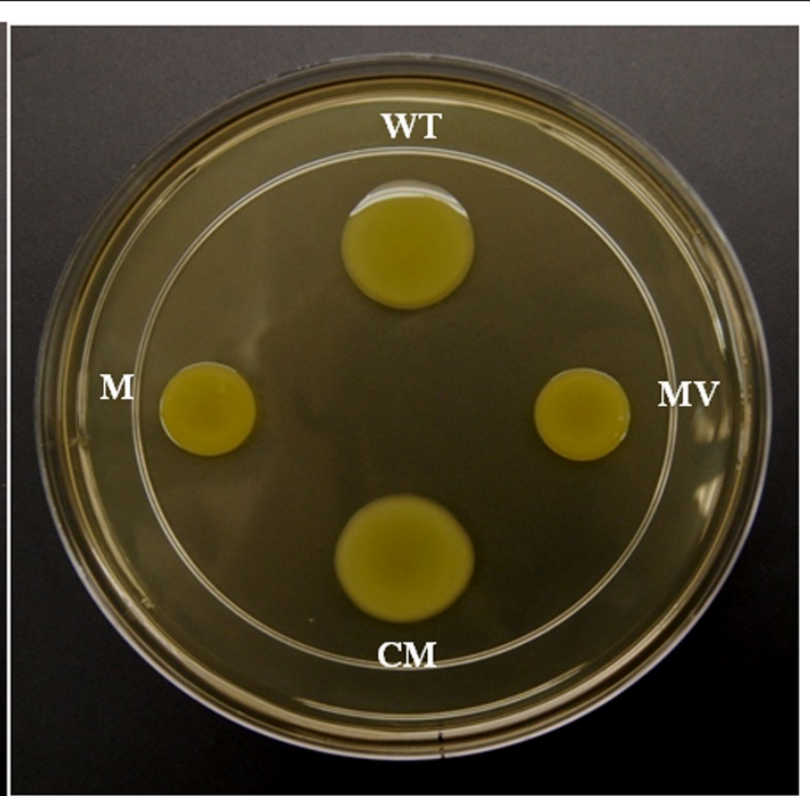

$0.60 \%$ agar plate

Figure 7 Motilities of $\boldsymbol{X}$. citri subsp. citri strains. Cells were inoculated onto NA plates supplemented with $0.25 \%$ or $0.60 \%$ agar from bacterial cultures at exponential stage and photographed after 3 days (0.25\% agar plate) and 7 days ( $0.60 \%$ agar plate) of incubation at room temperature (22-23ㄷ). WT: wild-type strain 306; M: gpsX mutant 223 G4 (gpsX-); MV: gpsX mutant 223G4V (gpsX-) with empty vector pUFR053; CM: complemented gps $X$ mutant C223G4 (gps $X+$ ). The gps $X$ mutant 223 G4 (gps $X-$ ) is reduced in cell motility, which could be restored to the wild-type level by providing a plasmid bearing the gps $X$ gene [i.e., the complemented strain C223G4 (gps $X+$ )] 
and $5 \mathrm{C}$ ) suggested that the gps $X$ gene might play a role in the adaptation of $X$. citri subsp. citri to the conditions of the host microenvironments. To test this hypothesis, the survival of the gps $X$ mutant was investigated under various stresses that would be likely experienced at the early stage of infection when the bacteria has to attach to the leaf surface and later when the bacteria has to survive inside the host plant, including UV radiation, heat shock, saline stress, osmotic challenge, desiccation stress, SDS exposure and the $\mathrm{H}_{2} \mathrm{O}_{2}$ oxidative stress. These assays revealed that the gps $X$ mutant $223 \mathrm{G} 4$ ( $g p s X$-) was more sensitive than the wild-type strain to UV radiation, heat shock, desiccation stress, SDS exposure, and $\mathrm{H}_{2} \mathrm{O}_{2}$ (Table 4). After $20 \mathrm{~min}$ of exposure to UV radiation, there were greater numbers of surviving cells of the wild-type strain than that of the gps $X$ mutant. Following 15 min of exposure of bacteria to heat $\left(50^{\circ} \mathrm{C}\right)$, viable cells of the gpsX mutant declined more rapidly than the wild-type. When exposed to air and dried for $60 \mathrm{~min}$, the gps $X$ mutant showed significantly decreased survival compared with the wild-type strain. After treatment with SDS (0.1\%) for $10 \mathrm{~min}$, the survival rate of the gps $X$ mutant was significantly lower than that of the wild-type strain. The gps $X$ mutant also showed higher sensitivity than the wild type strain to hydrogen peroxide (exposure to $0.03 \% \mathrm{H}_{2} \mathrm{O}_{2}$ for $20 \mathrm{~min}$ ). The levels of stress tolerance of the complemented strain were similar to those of the wild type (Table 4), indicating that the affected stress tolerance of the gps $X$ mutant could be restored by gps $X$ in trans. There were no differences between the gps $X$ mutant and wild type strain in survival under saline stress or osmotic challenge.

\section{Mutation of gpsX has no impact on expression of virulence-related genes}

Reduced virulence could result from down-regulation of key virulence genes. In order to test whether mutation of the $g p s X$ gene affected the expression of virulence-related genes, quantitative reverse transcription-PCR (QRT-PCR) assays were performed to monitor the expression profiles of six genes which were selected based on the alternated mutant phenotypes mentioned above. For total RNA preparation, the gps $X$ mutant and wild type strains were cultured to exponential phase in XVM2 medium that has been reported to mimic the environment of plant intercellular spaces [38]. The six target genes included one EPS biosynthesis gene $(\mathrm{gumB})$, one LPS synthesis gene $(r f b C)$, one catalase gene (katE), one TTSS component gene ( $h r c V$ ), one TTSS regulator genes $h r p X$, and one TTSS effector gene ( $p t h A)$. The results showed that none of the six genes was significantly differently expressed in the mutant 223 G4 (gpsX-) compared with wild-type strains when grown in XVM2 medium (Table 5), based on a student's t-test $(P<0.05)$. Specifically, the primer set used for pth $A$ is present in pthA4 and its homologues pthA1, $p t h A 2$, and $p t h A 3$, but not in any other genes. Thus we refer it as $p t h A$ rather than differentiating them. The qRTPCR result based on this primer should detect the expression of $p t h A 4, p t h A 1, p t h A 2$, and $p t h A 3$. It is very likely that pthA4, pthA1, pthA2, and pthA3 have similar gene expression pattern due to the same promoter sequences. The sequences are $100 \%$ identical in the $213 \mathrm{bp}$ upstream of $p$ thA4, pthA1, pthA2, and pthA3 including the predicated promoter region (data not shown). Consequently, the qRT-PCR result will represent the relative fold change in gene expression for $p t h A 4$, pthA1, pthA2, and/or $p t h A 3$ since it is relative fold change and not absolute expression value.

\section{Discussion}

In this work we have extended the characterization of the XAC3110 gene locus, previously identified and named $b d p 24$ for involvement in Xac biofilm formation [24]. We conclude from several independent lines of evidence that this gene is required for EPS and LPS biosynthesis, and consequently required for biofilm formation and full virulence of Xac on host plants. For this reason, we have

Table 4 Survival of the gpsX mutant and wild-type $X$. citri subsp. citri strain 306 under multiple stresses ${ }^{\mathrm{A}}$

\begin{tabular}{llllllll}
\hline Strains & \multicolumn{7}{c}{ Survival rate $(\%))^{\mathbf{B}}$} \\
\cline { 2 - 8 } & UV radiation & Heat shock & Desiccation tolerance & SDS exposure & $\mathbf{H}_{2} \mathbf{O}_{2}$ exposure & Osmolarity stress & Saline stress \\
\hline 306 & $3.2 \pm 1.2 \mathrm{a}$ & $0.04 \pm 0.02 \mathrm{a}$ & $2.7 \pm 0.7 \mathrm{a}$ & $10.1 \pm 3.1 \mathrm{a}$ & $1.6 \pm 0.5 \mathrm{a}$ & $4.9 \pm 2.3 \mathrm{a}$ & $6.1 \pm 2.4 \mathrm{a}$ \\
$223 \mathrm{G} 4$ (gps $X$-) & $0.9 \pm 0.3 \mathrm{~b}$ & $0.004 \pm 0.003 \mathrm{~b}$ & $0.4 \pm 0.1 \mathrm{~b}$ & $0.05 \pm 0.02 \mathrm{~b}$ & $0.05 \pm 0.02 \mathrm{~b}$ & $3.8 \pm 1.4 \mathrm{a}$ & $3.9 \pm 2.2 \mathrm{a}$ \\
$223 \mathrm{G} 4 \mathrm{~V}($ gps $X-)$ & $1.1 \pm 0.5 \mathrm{~b}$ & $0.005 \pm 0.003 \mathrm{~b}$ & $0.7 \pm 0.2 \mathrm{~b}$ & $0.08 \pm 0.03 \mathrm{~b}$ & $0.12 \pm 0.04 \mathrm{~b}$ & $4.1 \pm 1.7 \mathrm{a}$ & $5.5 \pm 1.7 \mathrm{a}$ \\
C223G4 (gps $X+)$ & $4.2 \pm 1.6 \mathrm{a}$ & $0.05 \pm 0.03 \mathrm{a}$ & $3.5 \pm 1.3 \mathrm{a}$ & $8.2 \pm 2.5 \mathrm{a}$ & $2.2 \pm 0.4 \mathrm{a}$ & $5.5 \pm 2.4 \mathrm{a}$ & $7.4 \pm 2.8 \mathrm{a}$ \\
\hline
\end{tabular}

ABacterial cell viability was estimated by plating on NA agar before (TO) and after (T1) the treatment. Percentage survival was calculated as the ratio of viable cell counts at T1 to that at T0. The treatments were applied as follows: for UV radiation, overnight bacterial culture was exposed to short-wave UV irradiation (254 $\mathrm{nm}$ ) for $20 \mathrm{~min}$; for heat-shock, bacterial culture was incubated at $50^{\circ} \mathrm{C}$ for $15 \mathrm{~min}$; for desiccation stress, bacterial culture was placed on glass coverslips and air dried in a laminar flow apparatus for $60 \mathrm{~min}$ and then resuspended in $0.85 \% \mathrm{NaCl}$ and plated; for SDS exposure, bacterial culture was treated with $0.1 \%$ SDS for $20 \mathrm{~min}$; for sensitivity to hydrogen peroxide, bacterial culture was exposed to $0.03 \% \mathrm{H}_{2} \mathrm{O}_{2}$ for 20 min; for osmotic stress, bacterial culture was treated with $40 \%$ D-sorbitol for $40 \mathrm{~min}$; for saline stress, bacterial culture was treated with $1.0 \mathrm{M} \mathrm{NaCl}$ for 20 min. Bacterial cells were serially diluted with NB medium and colonyforming units (cfu) were counted after being cultured on NA plates at $28^{\circ} \mathrm{C}$ for $48 \mathrm{~h}$. Each test, plated in triplicate, was repeated three times with similar results. ${ }^{\mathrm{B}}$ Data shown are means and standard errors of three replicates from one representative experiment. Different letters in each data column indicate significant differences at $P<0.05$ (Student's t-test). 
Table 5 Comparison of virulence gene expression in the wild type and the gpsX mutant cultured in XVM2 medium by QRT-PCR $^{a}$

\begin{tabular}{|c|c|c|c|c|c|}
\hline Gene & locus_tag & Function of protein product & $\Delta \Delta C_{T} \pm \mathrm{SD}^{b}$ & Fold change $\pm \mathrm{SD}^{c}$ & $P^{d}$ \\
\hline gumB & XAC2585 & EPS xanthan biosynthesis & $0.2665 \pm 0.1912$ & $0.8314 \pm 0.1102$ & 0.0524 \\
\hline$r f b C$ & XAC3598 & LPS O-antigen biosynthesis & $-0.2018 \pm 0.1467$ & $0.8695 \pm 0.0841$ & 0.0621 \\
\hline katE & XAC1211 & Monofunctional catalase & $0.0758 \pm 0.1346$ & $0.9485 \pm 0.0871$ & 0.4407 \\
\hline pthA & $N S^{e}$ & TTSS effector & $-0.1703 \pm 0.2407$ & $1.1253 \pm 0.1845$ & 0.3128 \\
\hline hrpX & XAC1266 & TTSS regulator & $0.2578 \pm 0.1638$ & $0.8364 \pm 0.0997$ & 0.2442 \\
\hline hrcV & XAC0405 & TTSS component & $0.1828 \pm 0.1348$ & $0.8811 \pm 0.0832$ & 0.1119 \\
\hline
\end{tabular}

${ }^{a}$ Both 16S rRNA and gyrA genes were used as endogenous controls in the QRT-PCR experiments and similar results were obtained when the data were normalized against the two genes respectively. Only the data obtained with 16S rRNA gene as control were shown.

${ }^{b}$ The mean $\triangle \triangle C_{T}$ was determined using four biological repeats. The experiment was repeated two times with similar results. Data from one experiment are shown.

${ }^{c}$ The expression change (mutant/wild type) in mutant $223 \mathrm{G} 4$ (gpsX-) was calculated using $2^{-\Delta \Delta C T}$.

${ }^{d} P$ value, analyzed by Student's $t$-test. Values are significantly different when $P$ is $<0.05$.

${ }^{e}$ No specific locus_tag. This represents the gene expression of pthA1, pthA2, pthA3 and pthA4.

changed the name of this gene to gps $X$, for glycosyltransferase for polysaccharide synthesis in Xac, to reflect the apparent multiple function of the gene product.

Several lines of evidence indicate that the gps $X$ locus is involved in polysaccharide biosynthesis. First, GpsX contains a glycosyltransferase family 2 domain and shares the conserved catalytic residues of glycosyltransferases (Figure 1 and 2). Second, mutation of gps $X$ resulted in decreased production of EPS (Figure 3A, Table 3) and altered LPS synthesis (Figure 3B), consistent with the general role of glycosyltransferases in polysaccharide biosynthesis $[12,13]$. Third, similar genes associated with polysaccharide biosynthesis have been identified in other bacterial pathogens (see below). Homologues of GpsX widely occur in the genomes of related phytopathogenic bacteria of Xanthomonas (Table 1). The biochemical characteristics and physiological roles of these homologous proteins remain unknown.

Some glycosyltransferase genes have already been identified in Xanthomonas spp. For example, as mentioned previously, the $r f b C$ gene encodes a glycosyltransferase, which serves as a truncated $\mathrm{O}$-antigen biosynthesis protein involved in LPS production in $X$. citri subsp. citri [23]. Both the ORFs XC_3814 and XC_3555 (xagB) in $X$. campestris pv. campestris are implicated in EPS production, but not LPS production [21,22]. In addition, the gumDMHKI genes encode different glycosyltransferases that direct the biosynthesis of the xanthan EPS in X. campestris pv. campestris $[39,40]$. However, these enzymes in Xanthomonas are mono-functional, i.e., involved either in EPS or LPS production. Our data showed that the gps $X$ gene is involved in both EPS and LPS production (Figure 3). The low similarities between GpsX and these proteins (data not shown) may suggest the differences in substrates and products.

Bacterial polysaccharides are usually synthesized from intracellular nucleotide sugar precursors and, most bacterial polysaccharides contain polymerized saccharide repeating units, the assembly of which involves glycosyltransferases that sequentially link monosaccharide moieties from nucleotide sugars to the growing sugar chain (saccharide acceptors) [11]. Different classes of bacterial polysaccharides can be distinguished on basis of their biosynthesis mechanisms and the precursors required. However, it is worth mentioning that, in some instances, mutation of single genes simultaneously affected biosynthesis of different polysaccharides, similar with the observation in this work. For example, in $X$. campestris pv. citrumelo, the mutation in ops $X$, a homologue of waaF ( $r f a F)$ which codes for a heptosyltransferase for LPS synthesis in E. coli, affected biosynthesis of LPS and EPS [41]. In addition, mutants in $x a n A$ and $x a n B$, involved in UDP-Glucose and GDP-Mannose biosynthesis in $X$. campestris pv. campestris, respectively, showed a decrease in EPS production and an altered LPS [42]. Mutants in galE, encoding a UDP-galactose epimerase in Erwinia amylovora, were deficient in EPS production and produced a LPS with an altered side chain structure [43]. The dual effect of certain genes on EPS and LPS may be due to the shared pathways for EPS and LPS synthesis in these bacteria. As discovered in Salmonella, the same precursor molecule, UDP-glucose, is used for LPS O-antigen polysaccharide and capsular polysaccharide [44]. The major EPS produced by xanthomonads, xanthan, composed of polymerized pentasaccharide repeating units, consisting of glucose, mannose and glucuronic acid [39]. Most recently, glucose and mannose were found to be components of LPS in X. citri subsp. citri [45]. Given the altered O-antigen containing LPS profile of the gpsX mutant and its decreased level of EPS production, it was likely that the gps $X$-encoded glycosyltransferase was involved in the formation of saccharide repeating units that might be found in X. citri subsp. citri EPS and LPS, by transferring the glucose and/or mannose monosaccharide moiety from certain nucleotide sugar precursors to corresponding acceptors. 
However, biochemical evidence for this proposed function of GpsX is needed.

Interestingly, the gps $X$ gene is located outside of the LPS gene cluster even though it is involved in the $\mathrm{O}$-antigen biosynthesis. The LPS cluster is responsible for synthesis of $\mathrm{O}$-antigen polysaccharide. The locus presents a size of $19.9 \mathrm{~kb}$ and contains 17 ORF $[7,46]$. The LPS cluster contains three glycosyltransferases, i.e. XAC3598 (RfbC), ORF5, and XAC3595. RfbC was annotated as a 614-amino-acid truncated O-antigen biosynthesis protein containing two separate glycosyltransferase family 2 (GT2) domains. The involvement of $r f b C$ in $\mathrm{O}$-antigen biosynthesis has been confirmed in our previous study [23]. The orf5 has been annotated to encode a putative glycosyltransferase [46], whereas XAC3595 shows significant homology to the glycosyltransferase A (GtrA) family [46]. It remains to be determined how GpsX and other glycosyltransferases are involved in $\mathrm{O}$-antigen biosynthesis in Xac.

The attenuation in virulence and growth in planta of the gps $X$ mutant both in epiphytic (Spray) and wound (pressure infiltration) inoculations (Figure 4 and 5) may result, at least partially if not completely, from the reduction in EPS production (Figure 3A) and the alteration of LPS profile (Figure $3 \mathrm{~B}$ ), and consequently impaired cell motility (Figure 7) and biofilm formation (Figure 6), rather than from an effect on the virulence genes (Table 5). EPS has been shown to act as an important virulence factor that contributes to epiphytic survival and/or bacterial in planta growth and disease symptom formation in several Xanthomonas spp. including $X$. campestris pv. campestris, $X$. oryzae pv. oryzae, and $X$. citri subsp. citri [8]. EPS can suppress plant basal defense responses by chelating divalent calcium that are require for the activation of plant defense responses $[47,48]$. It also contributes to biofilm formation $[21,24,34,49]$, which promotes bacterial resistance to environment stresses [23,36]. LPS has also been shown to be an important virulence factor in various plant pathogenic bacteria including several Xanthomonas spp. [8], Erwinia amylovora [50] and Pseudomonas syringae [51]. It can serve as a physical barrier protecting bacteria from plant defense responses [51]. It may also contribute to biofilm formation [23,24]. In addition, both EPS and LPS are related to cell motility in a couple of bacteria including $X$. citri subsp. citri $[21,24,37]$. In certain phytopathogenic bacteria, e.g., E. amylovora, P. syringae, and Ralstonia solanacearum, motility has been suggested to contribute to bacterial virulence in the early stages such as invasion and colonization [52-54]. X. citri subsp. citri is an intercellular space-colonizing pathogen that invades host plants via stomata or wounds, and multiplies in the apoplasts [4]. Before entering the host, the pathogen persists as epiphytes on the plant surface and has to confront environment stresses. Once entering the host, the pathogen needs to tolerate preformed defense molecules to establish a successful infection. Therefore, the alteration of LPS of the gpsX mutant and the reduction in its ability to produce EPS and to form biofilm formation may attenuate its adaptation to the conditions of the host microenvironment, which result in its growth deficiency, and consequently reduced virulence. Consistent with this, it has been demonstrated that both EPS and LPS biosyntheses are required for growth and survival on leaf surfaces and full virulence in $X$. citri subsp. citri [23,34]. Finally, gps $X$ may aid bacterial survival at early stage of infection when the bacterium attaches to the leaf surface and later survives inside the plant tissue. Consistent with the hypothesis, the gps $X$ mutant was attenuated in resistance against various stresses including oxidative stress (Table 4), which is one of the early plant defense responses triggered by bacterial infections [55].

In summary, in this work we expanded the knowledge about the function of the novel glycosyltransferase encoding gene gps $X$ from $X$. citri subsp. citri. Based on its apparently unique function in polysaccharide synthesis and the widely conserved occurrence in sequenced strains of Xanthomonas, this enzyme may represent a novel virulence-related factor of phytopathogenic Xanthomonas including $X$. citri subsp. citri. Additional study of this gene and its protein product should yield new insights into the biochemistry and physiological roles of bacterial glycosyltransferase of the citrus canker bacterium X. citri subsp. citri.

\section{Conclusions}

In this report we characterized the novel gps $X$ gene in $X$. citri subsp. citri. We demonstrated that the gps $X$ mutant is affected in EPS and LPS production, cell motility, biofilm formation, stress tolerance, growth in planta, and virulence on host plants and that the genetic complementation with the wild type gps $X$ gene, fully restored the affected phenotypes of the $g p s X$ mutant to wild-type levels. In conclusion, the gps $X$ gene is important for polysaccharide synthesis and biofilm formation and thus, plays an important role in the adaptation of $X$. citri subsp. citri to the host microenvironments at early stage of infection and required for full virulence on host plants.

\section{Methods}

Bacterial strains, plasmids and growth conditions

The bacterial strains and plasmids used in this study are listed in Table 2. E. coli strains were grown in LuriaBertani (LB) medium at $37^{\circ} \mathrm{C}$. Xac wild type strian306 (rifamycin resistant) and the EZ-Tn5 insertion mutant strain 223 G4 (gps $X-)$ have been described previously [24]. Xac strains were grown in nutrient broth/agar (NB/NA) or XVM2 medium [38] at $28^{\circ} \mathrm{C}$. Antibiotics were added at the following concentrations when required: ampicillin (Am) $50 \mu \mathrm{g} / \mathrm{ml}$; chloramphenicol 
(Cm), $35 \mu \mathrm{g} / \mathrm{ml}$; gentamycin (Gm), $5 \mu \mathrm{g} / \mathrm{ml}$; Kanamycin $(\mathrm{Km}), 50 \mu \mathrm{g} / \mathrm{ml}$; and rifamycin (Rf), $50 \mu \mathrm{g} / \mathrm{ml}$.

\section{DNA manipulations}

Bacterial genomic DNA and plasmid DNA were extracted using a Wizard genomic DNA purification kit and a Wizard miniprep DNA purification system following manufactuer's instructions (Promega, Madison, WI, USA). The concentration and purity of DNA were determined using a Nanodrop ND-1000 spectrophotometer (NanoDrop Technologies, Wilmington, DE, USA). The standard methods [56] were used for restriction digestion, DNA ligation, agarose gel electrophoresis and DNA transformation of E. coli. The restriction endonucleases, T4 DNA ligase and Pfu polymerase were provided by Promega (Promega Corporation, Madison, WI).

\section{Complementation of the gpsX mutant}

For complementation of the gps $X$ mutant $223 \mathrm{G} 4$ ( $g p s X-$ ), a 2,299-bp DNA fragment containing the intact open reading frame (ORF) of gps $X$ and 230 bp upstream of the 5 ' end to $21 \mathrm{bp}$ downstream of the 3' end of the ORF, was amplified from the genomic DNA of Xac strain 306 using the primers C10-F (5' -tcgaggtaccgttggtgtcgtcctcgaaat-3') and C10-R (5' - tcgtaagcttctcaccccgcaataaacaac-3'), respectively containing KpnI and HindIII restriction enzyme sites (underlined). The PCR product was digested with $K p n I$ and HindIII and cloned into the complementary vector pUFR053 [33] to construct the recombinant plasmid pJU3110 (Table 2). The recombinant plasmid was transferred into the gps $X$ mutant $223 \mathrm{G} 4$ (gpsX-) by triparental conjugation as described elsewhere [57], resulting in strain C233G4 (gps X+) (Table 2).

\section{Quantitative determination of EPS production}

To estimate EPS production, strains were cultured in $100 \mathrm{ml} \mathrm{NB}$ or XVM2 liquid medium containing 2\% (wt/vol) various sugars (fructose, galactose, glucose, maltose, mannose, sucrose, and xylose) at $28^{\circ} \mathrm{C}$ with shaking at $200 \mathrm{rpm}$ for 24 hours (in NB) or 48 hours (in XVM2). EPS was precipitated from the culture supernatant at different time point post inoculation with ethanol, dried, and weighed as described elsewhere [35].

\section{Lipopolysaccharides (LPS) analysis}

Bacterial strains were cultured at $28^{\circ} \mathrm{C}$ in NB or XVM2 liquid medium with shaking (200 rpm). Five-milliliter samples of cultures at the exponential stage were collected and the LPS samples were isolated as described previously [23]. LPS was separated by SDS-PAGE and visualized using silver staining following the manufacturer's instructions (Bio-Rad Laboratories, Inc., Hercules, CA). Standard LPS from Salmonella entenica serovar Typhimurium was obtained from Sigma. The test was performed three times independently.

\section{Capsule assays}

Bacterial capsules were stained using a capsule-staining kit (Eng Scientific Inc., Clifton, NJ, USA) following the manufacturer's instructions. The samples were photographed using a light microscope (Leica DMLB2; Leica Microsystems GmbH, Wetzlar, Germany) with a digital camera. The experiment was repeated three times.

\section{Biofilm formation assays}

Biofilm formation on polystyrene and glass surfaces were examined as described previously [23] with modifications. The average of four replicates was used for quantitative measurement. Assays of biofilm formation on leaf surfaces were conducted as described previously [58] with modifications. Briefly, $20 \mu \mathrm{l}$ of each bacterial suspension $\left(10^{8}\right.$ $\mathrm{cfu} / \mathrm{ml}$ ) was incubated on the abaxial surface of citrus leaves, and the leaves were kept at $28^{\circ} \mathrm{C}$ in a humidified chamber. After $24 \mathrm{~h}$ of incubation, biofilm formation on the leaf surface was visualized using crystal violet staining. The experiments were repeated three times.

\section{Motility assays}

To test cell motility, $2 \mu \mathrm{L}$ of bacterial cultures at the exponential stage in $\mathrm{NB}\left(\mathrm{OD}_{600}\right.$ of 0.8$)$ was spotted onto NA plates (diameter, $150 \mathrm{~mm}$; each containing $50 \mathrm{~mL}$ of NA) containing $0.25 \%$ (wt/vol) agar (Difco, Franklin Lakes, NJ) for swimming motility testing or $0.6 \%$ (wt/vol) agar for swarming motility testing. Plates were incubated at room temperature for 7 days. The diameters of the areas occupied by the strains were measured, and the values were used to indicate the motility of Xac strains. The experiment was repeated three times with three replicates each time.

\section{Electron microscopy}

For flagella visualization, cells grown on NA plates were harvested at 48 hours post inoculation (hpi) and suspended in $0.85 \% \mathrm{NaCl}$. One drop of cell suspension was placed onto a 400-mesh Formvar carbon-coated grid. Excess water was removed by blotting onto Whatman filter paper no. 1 (Whatman Inc, Piscataway, NJ, USA). One drop of $1 \%$ uranyl acetate solution was then added, and excess solution was removed. The grids were left at room temperature for $30 \mathrm{~min}$. Samples were viewed with a Philips FEI Morgagni 268 transmission electron microscope (FEI Company, Eindhoven, Netherlands) operating at $80 \mathrm{kV}$.

\section{Stress tolerance assays}

The assays were performed as described previously with modifications [23]. Bacterial culture at early exponential 
stage $\left(\mathrm{OD}_{600 \mathrm{~nm}}=0.1\right)$ in $\mathrm{NB}$ were used to test survival under stresses: UV radiation, heat shock, saline stress, osmotic challenge, desiccation stress, SDS stress and oxidative stress. In each stress treatment, cell viability was determined by plate-counting of cfu. The survival rate was defined as the percentage of viable cell counts from the culture with stress treatment compared with those from the non-treated culture. The stress treatments were applied as follows: for UV radiation, the cells were exposed to short-wave UV radiation $(254 \mathrm{~nm}$ in a biological safety cabinet) at a distance of $60 \mathrm{~cm}$ for $20 \mathrm{~min}$; for heat-shock stress, the culture was transferred to $50^{\circ} \mathrm{C}$ for $15 \mathrm{~min}$; for sodium stress, $\mathrm{NaCl}(\mathrm{pH}$ 7.5) was added to the bacterial culture at a final concentration of $1.0 \mathrm{M}$, and survival was estimated after 20 min, respectively; for osmotic challenge, D-sorbitol ( $\mathrm{pH}$ 7.0) was added to the bacterial culture at a final concentration of $40 \%$, and survival was estimated after $40 \mathrm{~min}$; for desiccation stress, the bacterial culture was placed on glass coverslips $(18 \mathrm{~mm} \times 18 \mathrm{~mm})$, air dried in a laminar flow apparatus for $60 \mathrm{~min}$ and then resuspended in $0.85 \% \mathrm{NaCl}$ and plated; for SDS stress, SDS ( $\mathrm{pH}$ 7.5) was added to the bacterial culture at a final concentration of $0.1 \%$, and survival was estimated after $10 \mathrm{~min}$; for oxidative stress, $\mathrm{H}_{2} \mathrm{O}_{2}$ was added to the bacterial culture at a final concentration of $0.03 \%$, and survival was estimated after $20 \mathrm{~min}$. Each stress test was repeated three times with three replicates each time. Student's $t$-test was used to test the significance of the differences.

\section{Pathogenicity assays}

Pathogenicity assays were performed as described previously [59]. Briefly, fully expanded, immature leaves of young (about 10-week-old) grapefruit (Citrus paradise cv. Duncan grapefruit) were prepared in a quarantine greenhouse at the Citrus Research and Education Center, Lake Alfred, FL. The X. citri subsp. citri strains were cultured for 2 days on NA plates at $28^{\circ} \mathrm{C}$ and were re-suspended in sterile tap water. A bacterial suspension $\left(10^{8}\right.$ or $10^{5} \mathrm{cfu} / \mathrm{ml}$ ) was injected into the intercellular spaces of leaves with a needleless syringe; and a bacterial suspension $\left(10^{8} \mathrm{cfu} / \mathrm{ml}\right)$ was inoculated on the leaf abaxial surface by a spray method. All plant inoculations involved a minimum of three immature leaves at a similar developmental stage from each plant, and three plants were inoculated for each bacterial strain. All the tests were repeated three times independently.

\section{Bacterial growth assays in planta}

For in planta growth assays, bacterial strains were inoculated onto leaves of grapefruit as described above. Leaf discs $(0.8 \mathrm{~cm}$ in diameter) randomly selected from inoculated leaves were excised with a cork borer and then ground in $1 \mathrm{~mL}$ of $0.85 \%(\mathrm{w} / \mathrm{v}) \mathrm{NaCl}$. The suspension were serially diluted and plated on NA plates containing appropriate antibiotics. Bacterial colonies were counted after incubation at $28^{\circ} \mathrm{C}$ for $48 \mathrm{~h}$ and the number of cfu per square centimeter of leaf tissue was calculated. The in planta growth was measured in quadruplicate and the assays were repeated three times independently.

\section{RNA prepare and quantitative reverse transcription-PCR (QRT-PCR)}

Total RNA of $X$. citri subsp. citri cells cultured in XVM2 medium at exponential phase (14 h after inoculation) was isolated using RNA protect bacterial reagent (Qiagen, Valencia, CA) and RNeasy Mini Kit (Qiagen, Valencia, CA) and contaminated genomic DNA was removed using a TURBO DNA-free kit (Ambion, Austin, TX), following the manufacturer's instructions. RNA purity and quality were assessed with a NanoDrop ND1000 spectrophotometer (NanoDrop Technologies, Wilmington, DE).

A one-step QRT-PCR was performed with a 7500 fast real-time PCR system (Applied Biosystems, Foster City, CA) using a QuantiTect SYBR green RT-PCR kit (Qiagen, Valencia, CA) following the manufacturer's instructions. The gene specific primers used were previously designed $[35,59]$, except the DNA gyrase subunit A encoding gene gyrA (FP: 5' -CGTCACGTTGATCCGTTTGT-3' ; RP: 5' -GCTTGCTTCGTCCACTCCCT-3'), based on the genome sequence of strain 306 . Those primers targeted the gum gene gumB, LPS O-antigen biosynthesis related gene $r f b C$, TTSS genes $h r p X$ and $h r c V$, a catalase gene $k a t E$, the virulence factor $p t h A$. The $16 \mathrm{~S}$ rRNA and gyrA genes were used as endogenous controls. The relative fold change in target gene expression was calculated by using the formula $2^{-\Delta \Delta C T}[60]$. QRT-PCR was repeated twice with four independent biological replicates each time.

\section{Acknowledgements}

This work has been supported by Citrus Research and Education Foundation.

\section{Author details}

'Citrus Research and Education Center, Department of Microbiology and Cell Science, University of Florida, IFAS, 700 Experiment Station Road, Lake Alfred FL 33850, USA. ${ }^{2}$ Department of Plant Pathology, China Agricultural University, Beijing 100193, China.

Authors' contributions

$J$ and NW conceived and designed the experiments, performed the experiments, analyzed the data and wrote the paper. All authors read and approved the final manuscript

Received: 21 November 2011 Accepted: 9 March 2012

Published: 9 March 2012

\section{References}

1. Vauterin L, Hoste B, Kersters K, Swings J: Reclassification of Xanthomonas. Int J Syst Bacteriol 1995, 45:472-489. 
2. Schaad N, Postnikova E, Lacy G, Sechler A, Agarkova I, Stromberg P, Stromberg V, Vidaver A: Emended classification of xanthomonad pathogens on citrus. Syst Appl Microbiol 2006, 29:690-695.

3. Gottwald TR, Graham JH, Schubert TS: Citrus canker: the pathogen and its impact. Plant Health Prog 2002, doi:10.1094/PHP-2002-0812-01-RV.

4. Graham JH, Gottwald TR, Cubero J, Achor DS: Xanthomonas axonopodis pv. citri: factors affecting successful eradication of citrus canker. Mol Plant Pathol 2004, 5:1-15.

5. Gottwald TR, Graham JH, Bock C, Bonn G, Civerolo E, Irey M, Leite R, McCollum G, Parker P, Ramallo J, Riley T, Schubert T, Stein B, Taylor E: The epidemiological significance of post-packinghouse survival of Xanthomonas citri subsp. citri for dissemination of Asiatic citrus canker via infected fruit. Crop Prot 2009, 28:508-524.

6. Behlau F, Belasque J, Graham JH, Leite RP: Effect of frequency of copper applications on control of citrus canker and the yield of young bearing sweet orange trees. Crop Prot 2010, 29:300-305.

7. da Silva AC, Ferro JA, Reinach FC, Farah CS, Furlan LR, Quaggio RB, Monteiro-Vitorello CB, Van Sluys MA, Almeida NF, Alves LM, do Amaral AM, Bertolini MC, Camargo LE, Camarotte G, Cannavan F, Cardozo J, Chambergo F, Ciapina LP, Cicarelli RM, Coutinho LL, Cursino-Santos JR, ElDorry H, Faria JB, Ferreira AJ, Ferreira RC, Ferro MI, Formighieri EF, Franco MC, Greggio CC, Gruber A, Katsuyama AM, Kishi LT, Leite RP, Lemos EG, Lemos MV, Locali EC, Machado MA, Madeira AM, MartinezRossi NM, Martins EC, Meidanis J, Menck CF, Miyaki CY, Moon DH, Moreira LM, Novo MT, Okura VK, Oliveira MC, Oliveira VR, Pereira HA, Rossi A, Sena JA, Silva C, de Souza RF, Spinola LA, Takita MA, Tamura RE, Teixeira EC, Tezza Rl, Trindade dos Santos M, Truffi D, Tsai SM, White FF, Setubal JC, Kitajima JP: Comparison of the genomes of two Xanthomonas pathogens with differing host specificities. Nature 2002, 417:459-463.

8. Büttner D, Bonas U: Regulation and secretion of Xanthomonas virulence factors. FEMS Microbiol Rev 2010, 34:107-133.

9. Ryan RP, Vorhölter FJ, Potnis N, Jones JB, Van Sluys MA, Bogdanove AJ, Dow JM: Pathogenomics of Xanthomonas: understanding bacteriumplant interactions. Nat Rev Microbio 2011, 9:344-355.

10. Rico A, Jones R, Preston GM: Adaptation to the plant apoplast by plant pathogenic bacteria. In Plant Pathogenic Bacteria: Genomics and Molecular Biology. Edited by: Jackson RW. Norfolk: Caister Academic Press; 2009:63-89.

11. Ullrich M: Bacterial Polysaccharides: Current Innovations and Future Trends Norwich: Caister Academic Press; 2009.

12. Breton C, Snajdrova L, Jeanneau C, Koca J, Imberty A: Structures and mechanisms of glycosyltransferases. Glycobiology 2006, 16:29R-37R.

13. Lairson LL, Henrissat B, Davies GJ, Withers SG: Glycosyltransferases: structures, functions, and mechanisms. Annu Rev Biochem 2008, 77:521-555.

14. Power PM, Jennings MP: The genetics of glycosylation in Gram-negative bacteria. FEMS Microbiol Lett 2003, 218:211-222.

15. Campbell JA, Davies GJ, Bulone V, Henrissat B: A classification of nucleotide diphospho-sugar glycosyltransferases based on amino acid sequence similarities. Biochem J 1997, 326:929-939.

16. Cantarel BL, Coutinho PM, Rancurel C, Bernard T, Lombard V, Henrissat B: The Carbohydrate-Active EnZymes database (CAZy): an expert resource for Glycogenomics. Nucleic Acids Res 2009, 37:D233-D238.

17. Charnock SJ, Davies GJ: Structure of the nucleotide-diphospho-sugar transferase, SpsA from Bacillus subtilis, in native and nucleotidecomplexed forms. Biochemistry 1999, 38:6380-6385.

18. Benz I, Schmidt MA: Glycosylation with heptose residues mediated by the aah gene product is essential for adherence of the AIDA-I adhesin. Mol Microbiol 2001, 40:1403-1413.

19. Wang X, Preston JF: Romeo T: The pgaABC locus of Escherichia coli promotes the synthesis of a polysaccharide adhesin required for biofilm formation. J Bacteriol 2004, 186:2724-2734.

20. Arora SK, Bangera M, Lory S, Ramphal R: A genomic island in Pseudomonas aeruginosa carries the determinants of flagellin glycosylation. Proc. Natl Acad Sci. USA 2001, 98:9342-9347.

21. Tao F, Swarup F, Zhang LH: Quorum sensing modulation of a putative glycosyltransferase gene cluster essential for Xanthomonas campestris biofilm formation. Environ Microbiol 2010, 12:3159-3170.

22. Lu GT, Ma ZF, Hu JR, Tang DJ, He YQ, Feng JX, Tang JL: A novel locus involved in extracellular polysaccharide production and virulence of Xanthomonas campestris pathovar campestris. Microbiology 2007, 153:737-746.
23. Li J, Wang N: The wxacO gene of Xanthomonas citri ssp. citri encodes a protein with a role in lipopolysaccharide biosynthesis, biofilm formation, stress tolerance and virulence. Mol Plant Pathol 2011, 12:381-396.

24. Li J, Wang N: Genome-wide mutagenesis of Xanthomonas axonopodis pv. citri reveals novel genetic determinants and regulation mechanisms of biofilm formation. PLOS ONE 2011, 6:e21804.

25. Caspi R, Altman T, Dale JM, Dreher K, Fulcher CA, Gilham F, Kaipa P, Karthikeyan AS, Kothari A, Krummenacker M, Latendresse M, Mueller LA, Paley S, Popescu L, Pujar A, Shearer AG, Zhang P, Karp PD: The MetaCyc database of metabolic pathways and enzymes and the BioCyc collection of pathway/genome databases. Nucleic Acids Res 2010, 38:D473-D479.

26. Finn R, Tate J, Mistry J, Coggill P, Sammut S, Hotz HR, Ceric G, Forslund K, Eddy S, Sonnhammer E, Bateman A: The Pfam protein families database. Nucl Acids Res 2008, 36:D281-D288.

27. Qasba PK, Ramakrishnan B, Boeggeman E: Substrate-induced conformational changes in glycosyltransferases. Trends Biochem Sci 2005, 30:53-62.

28. Tarbouriech N, Charnock SJ, Davies GJ: Three-dimensional structures of the $\mathrm{Mn}$ and $\mathrm{Mg}$ dTDP complexes of the family GT-2 glycosyltransferase SpsA: a comparison with related NDP-sugar glycosyltransferases. J Mol Biol 2001, 314:655-661.

29. Hanahan F: Studies on transformation of Escherichia coli with plasmids. J Mol Biol 1983, 166:557-580.

30. Boyer $H$, Roulland-Dussoix D: A complementation analysis of the restriction and modification of DNA in Escherichia coli. J Mol Biol 1969, 41:459-472.

31. Rybak M, Minsavage GV, Stall E, Jones JB: Identification of Xanthomonas citri subsp. citri host specificity genes in a heterologous expression host. Mol Plant Pathol 2009, 10:249-262.

32. Figurski DH, Helinski DR: Replication of an origin-containing derivative of plasmid RK2 dependent on a plasmid function provided in trans. Proc Natl Acad Sci USA 1979, 76:1648-1652.

33. El Yacoubi B, Brunings A, Yuan Q, Shankar S, Gabriel D: In planta horizontal transfer of a major pathogenicity effector gene. Appl Environ Microbiol 2007, 73:1612-1621.

34. Rigano LA, Siciliano F, Enrique R, Sendin L, Filippone P, Torres PS, Questa J, Dow JM, Castagnaro AP, Vojnov AA, Marano MR: Biofilm formation, epiphytic fitness, and canker development in Xanthomonas axonopodis pv. citri. Mol Plant-Microbe Interact 2007, 20:1222-1230.

35. Guo Y, Sagaram US, Kim JS, Wang N: Requirement of the galU gene for polysaccharide production by and pathogenicity and growth in planta of Xanthomonas citri subsp. citri. Appl Environ Microbiol 2010, 76:2234-2242.

36. Danhorn T, Fuqua C: Biofilm formation by plant-associated bacteria. Annu Rev Microbiol 2007, 61:401-422.

37. Malamud F, Torres PS, Roxana R, Rigano LA, Enrique R, Bonomi HR, Castagnaro AP, Marano MR, Vojnov AA: Xanthomonas axonopodis pv. citri flagellum is required for mature biofilm and canker development. Microbiology 2011, 157:819-829.

38. Wengelnik K, Marie C, Russel M, Bonas U: Expression and localization of HrpA1, a protein of Xanthomonas campestris pv. vesicatoria essential for pathogenicity and induction of the hypersensitive reaction. $J$ Bacteriol 1996, 178:1061-1069.

39. Vorholter FJ, Schneiker S, Goesmann A, Krause L, Bekel T, Kaiser O, Linke B, Patschkowski T, Ruckert C, Schmid J, Sidhu VK, Sieber V, Tauch A, Watt SA, Weisshaar B, Becker A, Niehaus K, Puhler A: The genome of Xanthomonas campestris pv. campestris B100 and its use for the reconstruction of metabolic pathways involved in xanthan biosynthesis. J Biotechno 2008, 134:33-45.

40. Salinas SR, Bianco Ml, Barreras M, lelpial L: Expression, purification and biochemical characterization of Guml, a monotopic GDP-mannose: glycolipid 4- $\beta$-D-mannosyltransferase from Xanthomonas campestris pv. campestris. Glycobiology 2011, 21:903-913.

41. Kingsley MT, Gabriel DW, Marlow GC, Roberts PD: The opsX locus of Xanthomonas campestris affects host range and biosynthesis of lipopolysaccharide and extracellular polysaccharide. J Bacterio/ 1993, 175:5839-5850.

42. Köplin R, Arnold W, Hötte B, Simon R, Wang G, Pühler A: Genetics of xanthan production in Xanthomonas campestris: the xanA and xanB genes are involved in UDP-glucose and UDP-mannose biosynthesis. $J$ Bacteriol 1992, 174:191-199. 
43. Metzer M, Bellemann P, Bugert P, Geider K: Genetics of galactose metabolism of Erwinia amylovora and its influence on polysaccharide synthesis and virulence of the fire blight pathogen. J Bacteriol 1994, 176:450-459.

44. Anriany Y, Sahu SN, Wessels KR, McCann LM, Joseph SW: Alteration of the rugose phenotype in waaG and ddhC mutants of Salmonella enterica serovar Typhimurium DT104 is associated with inverse production of curli and cellulose. Appl Environ Microbiol 2006, 72:5002-5012.

45. Casabuono A, Petrocelli S, Ottado J, Orellano EG, Couto AS: Structural analysis and involvement in plant innate immunity of Xanthomonas axonopodis pv. citri lipopolysaccharide. J Biol Chem 2011, 286:25628-25643.

46. Patil PB, Bogdanove AJ, Sonti RV: The role of horizontal transfer in the evolution of a highly variable lipopolysaccharide biosynthesis locus in xanthomonads that infect rice, citrus and crucifers. BMC Evol Biol 2007, 7:243.

47. Yun MH, Torres PS, El Oirdi M, Rigano LA, Gonzalez-Lamothe R, Marano MR, Castagnaro AP, Dankert MA, Bouarab K, Vojnov AA: Xanthan induces plant susceptibility by suppressing callose deposition. Plant Physiol 2006, 141:178-187.

48. Aslam SN, Newman MA, Erbs G, Morrissey KL, Chinchilla D, Boller T, Jensen TT, De Castro C, lerano T, Molinaro A, Jackson RW, Knight MR, Cooper RM: Bacterial polysaccharides suppress induced innate immunity by calcium chelation. Curr Biol 2008, 18:1078-1083.

49. Torres PS, Malamud F, Rigano LA, Russo DM, Marano MR, Castagnaro AP, Zorreguieta A, Bouarab K, Dow JM, Vojnov AA: Controlled synthesis of the DSF cell-cell signal is required for biofilm formation and virulence in Xanthomonas campestris. Environ Microbiol 2007, 9:2101-2109.

50. Berry MC, McGhee GC, Zhao Y, Sundin GW: Effect of a waaL mutation on lipopolysaccharide composition, oxidative stress survival, and virulence in Erwinia amylovora. FEMS Microbiol Lett 2009, 291:80-87.

51. Deng WL, Lin YC, Lin RH, Wei CF, Huang YC, Peng HL, Huang HC: Effects of galU mutation on Pseudomonas syringae plant interactions. Mol Plant Microbe Interact 2010, 23:1184-1196.

52. Bayot RG, Ries SM: Role of motility in apple blossom infection by Erwinia amylovora and studies of fire blight control with attractant and repellent compounds. Phytopathology 1986, 76:441-445.

53. Hatterman DR, Ries SM: Motility of Pseudomonas syringae pv. glycinea and its role in infection. Phytopathology 1989, 79:284-289.

54. Tans-Kersten J, Huang H, Allen C: Ralstonia solanacearum needs motility for invasive virulence on tomato. J Bacteriol 2001, 183:3597-3605.

55. Nanda AK, Andrio E, Marino D, Pauly N, Dunand C: Reactive oxygen species during plant-microorganism early interactions. J Integr Plant Biol 2010, 52:195-204.

56. Sambrook J, Russell DW: Molecular cloning: A laboratory manual Cold Spring Harbor Press: Cold Spring Harbor; 2001.

57. Swarup S, De Feyter R, Brlansky RH, Gabriel DW: A pathogenicity locus from Xanthomonas citri enables strains from several pathovars of Xanthomonas campestris to elicit canker-like lesions on citrus. Phytopathology 1991, 81:802-809.

58. Gottig N, Garavaglia BS, Garofalo CG, Orellano EG, Ottado J: A filamentous hemagglutinin-like protein of Xanthomonas axonopodis pv. citri, the phytopathogen responsible for citrus canker, is involved in bacterial virulence. PLOS ONE 2009, 4:e4358.

59. Yan Q, Wang N: The ColR/ColS two-component system plays multiple roles in the pathogenicity of the citrus canker pathogen Xanthomonas citri subsp. citri. J Bacteriol 2011, 193:1590-1599.

60. Livak K, Schmittgen T: Analysis of relative gene expression data using real-time quantitative PCR and the 2-DeltaDeltaCT method. Methods 2001, 25:402-408.

doi:10.1186/1471-2180-12-31

Cite this article as: Li and Wang: The gps $X$ gene encoding a glycosyltransferase is important for polysaccharide production and required for full virulence in Xanthomonas citri subsp. citri. BMC Microbiology 2012 12:31.

\section{Submit your next manuscript to BioMed Central and take full advantage of:}

- Convenient online submission

- Thorough peer review

- No space constraints or color figure charges

- Immediate publication on acceptance

- Inclusion in PubMed, CAS, Scopus and Google Scholar

- Research which is freely available for redistribution 